\title{
Lazer, bairro e escola no depoimento de jovens protagonistas de violência
}

\author{
Leisure, neighborhood and school: the testimony of young protagonists of violence \\ Ocio, barrio y escuela en lo testimonio de jóvenes protagonistas de violencia
}

\author{
LUCIANO PLEZ DE MELO 1 \\ LEILA MARIA FERREIRA SALLES ${ }^{1} 1$ \\ ${ }^{1}$ Universidade Estadual Paulista, Rio Claro, SP, Brasil.
}

$\diamond$

\begin{abstract}
RESUMO
Este trabalho tem por objetivo compreender os modos de inserção social de jovens protagonistas de violência em espaços de estadas cotidianas, como o bairro, os locais de lazer e a escola. Foram realizadas entrevistas focais com dois grupos de jovens matriculados em duas escolas públicas localizadas em bairros da periferia urbana empobrecida de uma cidade do interior de São Paulo e, pelas próprias escolas, considerados como protagonistas de violência. As regularidades discursivas presentes nos depoimentos foram analisadas. Os depoimentos apontaram que os modos de inserção social dos jovens trazem marcas acentuadas que são decorrentes da moradia em um conjunto de bairros que concentra, de acordo com dados do Censo de 2010, 7\% da população do município, e que tais marcas adentram todos os locais de estada cotidiana, inclusive a escola. Os jovens, contudo, parecem desconsiderar as determinações externas que configuram as características dos locais que frequentam e as estadas em comum, o que dificulta o estabelecimento de vínculos que favoreçam a sua agregação e resistência às situações que vivem.
\end{abstract}

Palavras-chave: Jovens. Inserção social. Escola.

\begin{abstract}
This paper aims to understand the ways of social inclusion of young protagonists of violence in their everyday living spaces such as the neighborhood, areas of leisure and the school. Focal interviews were conducted with two groups of young people enrolled in two public schools located in impoverished urban suburbs of a city in the interior of São Paulo and by the schools themselves, considered to be protagonists of violence. The discursive regularities present in the testimonies were analyzed. The testimonies point out that the social insertion methods of the youngsters are marked by the accentuated signs of housing in a set of neighborhoods that, according to the 2010 Census, account for $7 \%$ of the population of the municipality, and that such marks enter all the places of daily stay, including the school. Young people, however, appear to disregard the external determinations that shape the characteristics of the places they frequent. It hinders the establishment of links that favor the aggregation and resistance to situations in which they live.
\end{abstract}

Keywords: Youth. Social inclusion. School.

\section{RESUMEN}

Este estudio tiene como objetivo comprender las formas de inclusión social de los jóvenes protagonistas de la violencia en las zonas de estancia de todos los días como el barrio, sitios de ocio y la escuela. Entrevistas focales se llevaron a cabo con dos grupos de jóvenes considerados protagonistas de violencia por las escuelas, e que asisten a dos escuelas públicas ubicadas en los distritos de la periferia urbana empobrecida de una ciudad en el Estado de São Paulo. Se analizaron las regularidades discursivas en los testimonies. Los testimonios apuntan que los modos de inserción social de los jóvenes traen marcas acentuadas que se derivan de la vivienda en un conjunto de barrios que concentra, de acuerdo con datos del Censo de 2010, el 7\% de la población del municipio, y que tales marcas adentran todos lugares de estancia cotidiana, incluso la escuela. Los jóvenes, sin embargo, parecen no tener en cuenta las determinaciones externas que constituyen las características de los lugares que frecuentan, por lo que es difícil establecer vínculos que favorecen su agregación y la resistencia a las situaciones de vida.

Palabras clave: Juventud. Inclusión social. Escuela. 


\section{INTRODUÇÃO}

A proposta deste trabalho é caracterizar e analisar os modos de inserção social de jovens considerados protagonistas de violência na comunidade onde vivem, nos espaços de lazer e na escola. Para isso, focou-se nos modos cotidianos de inserção social dos jovens expressos em suas relações de amizade, lazer, obrigações, escola e trabalho.

Este estudo foi desenvolvido em uma região de uma cidade do interior do Estado de São Paulo - Rio Claro $^{1}$ - na qual os indicadores ${ }^{2}$ sociais de violência, criminalidade e pobreza são elevados. É um conjunto de bairros que apresenta grande densidade demográfica e baixo índice socioeconômico. A infraestrutura é precária e predominam habitações de padrão popular. Não existem áreas verdes, nem áreas destinadas ao lazer da população local. Há uma quadra esportiva em fase de construção, já depredada, mas que mesmo assim é utilizada pelos jovens da comunidade. Além disso, várias igrejas que professam os mais diferentes credos, com maior incidência de igrejas de matrizes católicas e pentecostais estão instaladas na localidade. Um elevado número de bares também compõe o espaço. As atividades econômicas estão ligadas ao comércio de pequeno porte e ao setor de serviço informal. Essa área é considerada uma das mais violentas do município. Nos bairros que abrange, roubos, furtos, brigas, mortes, ação policial e uso de entorpecentes são fatos cotidianos. Muitos dos jovens entrevistados têm familiares presos.

Nessa região da cidade estão localizadas duas escolas frequentadas pelos jovens que participaram deste estudo. As escolas atendem alunos do Ensino Fundamental Ciclo II e alunos do Ensino Médio. O prédio da escola que denominaremos aqui de Escola 1 estava bastante depredado; o muro ao redor estava quebrado e sua pintura encontrava-se suja e pichada. A escola não causou boa impressão. $\mathrm{O}$ estado aparente foi de abandono e penúria. $\mathrm{O}$ prédio era escuro e aparentava poucos cuidados com a higiene do local. Muitas vezes, policiais adentram o prédio para procurar foragidos e até mesmo realizar batidas $^{3}$ em busca de alunos supostamente ligados ao crime. Algumas vezes, com armas em punho e efetuando prisões ${ }^{4}$. A escola mostrava marcas de vandalismo e de invasões, que são quase diárias

\footnotetext{
1 A omissão da designação do conjunto de bairros deve-se à manutenção do sigilo das escolas e alunos partícipes da pesquisa.

2 Dados consultados junto ao site oficial da Secretaria da Segurança Pública do Governo do Estado de São Paulo. Disponível em: https://www.ssp. sp.gov.br/Estatistica/Pesquisa.aspx. Acesso em: 7 jan. 2019.

3 Termo usualmente utilizado no local para incursões policiais nas dependências da escola com fins a averiguação / captura de suspeitos de algum ilícito.

${ }^{4}$ Fato narrado por alunos durante realização de entrevistas com grupos focais.
}

A outra escola, a Escola 2, por outro lado, já causou uma boa impressão. O prédio era muito bem cuidado, limpo e sem pichações. Existia uma constante preocupação da direção com a conservação do prédio escolar. Segundo os gestores, a violência doméstica, a falta de assistência básica em saúde e alimentação, o acesso precoce ao mercado de trabalho e o uso de drogas ilícitas fazem parte da vida dos alunos. Isso, porém é recente na história dessa instituição, que sempre foi considerada uma escola que, embora situada em um bairro da periferia urbana empobrecida, não apresentava problemas como absenteísmo, episódios de violência entre alunos/alunos e alunos/educadores, pichações ou uso de drogas.

Foram feitas entrevistas focais (GATTI, 2005) com jovens matriculados nessas duas escolas, considerados protagonistas de violência pela equipe gestora: diretores e coordenadores. Em cada escola foi constituído um grupo, que denominaremos aqui de GV1 e GV2, em acordo com suas matriculas na Escola 1 ou na Escola 2. Os grupos contavam com alunos matriculados nas $8^{\underline{a}}$ e 9 ${ }^{\underline{a}}$ séries do Ensino Fundamental e 1o ano do Ensino Médio. Nos grupos, constituídos por cinco e nove alunos respectivamente nos GV1 e GV2, embora os participantes fossem predominantemente do sexo masculino, tanto meninas como meninos participaram das entrevistas e suas idades variavam ente 14 e 17 anos $^{5}$. Os temas geradores foram: lazer, obrigações, escola, estudos, amigos, jovens do bairro, lugares frequentados e comunidade onde vive. Solicitamos a cada participante que se posicionasse frente a esses temas, procurando incentivar a discussão entre eles a respeito de cada temática. No total, foram realizadas quatro entrevistas focais, duas com cada grupo.

Para definir as categorias de análise, as respostas dos jovens foram classificadas e categorizadas em diferentes blocos temáticos definidos a partir da revisão da bibliografia e do discurso dos participantes. A técnica empregada para o exame dos depoimentos foi análise de conteúdo que, segundo Bardin (1988), é um instrumental metodológico através do qual se busca entender o sentido de uma comunicação. As regularidades discursivas presentes nos depoimentos foram analisadas.

\section{SOBRE JOVENS, JOVENS DE PERIFERIA E INSERÇÃO SOCIAL}

A juventude tem sido considerada uma categoria social que reúne sujeitos que compartilham a mesma fase da vida, entendida como um estágio intermediário

\footnotetext{
${ }^{5}$ Este estudo foi submetido ao Comitê de Ética em pesquisa com seres humanos, sendo que os responsáveis pelos jovens $=$ menores de idade participantes assinaram o Termo de Consentimento Livre e Esclarecido (TCLE), obedecendo assim ao estabelecido para a pesquisa científica em Ciências Humanas.
} 
entre a infância e a idade adulta e como um período transitório no qual as responsabilidades são menores. A juventude é representada socialmente como um tempo de permissividade, de diversão, de irreverência às instituições e aos valores do mundo adulto (SALLES, 1998).

Quando a ênfase recai na juventude como etapa da vida a distinção entre mundo adulto e mundo jovem é acentuada e investigada nos estudos. Também a cultura, os estilos de vida juvenis, o lazer e as atividades realizadas no período de ócio são estudados e analisados na medida em que a diversidade de gênero, raça/etnia, classe social, religião, estilos musicais, entre outros, imprimem diferenciações entre a população jovem, tornando-a diversificada e heterogênea (ABRAMOVAY et al., 2009; DAYRELL, 2005; HERSCHMANN, 2000).

O jovem, no entanto, ressaltamos aqui, é sobretudo influenciado e constitui-se a partir do contexto sociocultural em que vive; assim, a escolarização, o uso do tempo livre, a disponibilidade de lazer, entre outros, se inscrevem conforme a condição econômica (ABRAMO, 1994; ABRAMOVAY, 2002, 2009; DAYRELL, 2005; HERSCHMANN, 2000). A ausência de trabalho e a pobreza, associados às desigualdades sociais delimitam espaços e modos de inserção social (LOPES, 2006; RIBEIRO, 2006).

Para Pais (1990) as diferentes reflexões e teorias sobre juventude podem ser agrupadas em duas principais correntes: a geracional e a classista. Ora o foco da discussão é a relação entre gerações e ora o centro das discussões são as relações de classe. A corrente classista questiona a homogeneidade proposta pela corrente geracional na medida em que as diferenças sociais e culturais entre os jovens são interpretadas como produtos das desigualdades estruturais de uma sociedade capitalista. As teorias classistas, ao postularem que o modo de ser jovem tem estrita relação com o extrato socioeconômico ao qual pertence, desmascaram a aparente homogeneidade da juventude que é sublimada nos discursos políticos e nas intervenções administrativas. Para a corrente classista, os espaços frequentados pelos jovens, os estilos musicais, a forma de se vestir, os gostos, as preferências e os estilos de vida são produtos diretos das condições econômicas em que vivem. E é nesse sentido, conforme diz Dayrell (2005), que podem ser interpretados como símbolos de pertença a uma determinada classe social.

Nesse texto, os dois polos da relação são considerados: juventude refere-se a uma etapa de vida que, porém, é vivida de forma distinta, segundo os estratos sociais aos quais os jovens pertencem, e que determinam modos específicos de inserção social. Isso implica que as referências e análises feitas aqui sobre os modos de inserção social dos jovens na localidade onde vivem, nos espaços que frequentam e na escola buscam considerar a juventude como uma etapa da vida que iguala os jovens participantes do estudo a todos os demais, mas que também apresentam maneiras de ser que lhe são próprias, pois são jovens pertencentes aos extratos socioeconômicos mais desfavorecidos da população, residentes na periferia urbana e considerados protagonistas de violência pelos educadores.

Embora a referência à periferia neste estudo tenha por intenção situar as análises, isso não implica que toda periferia possa ser caracterizada como pobre e o centro da cidade como rico, mas ter como referência o jovem pobre e morador da periferia urbana implica em considerar as especificidades expressas nos espaços que frequentam, nos estilos musicais que adotam, nos gostos e preferências que manifestam, nos estilos de vida que abraçam e ponderar também a segregação, a exclusão social e as representações sociais a que estão sujeitos.

Em geral, há uma percepção que tende a igualar jovens, pobres e de periferia com desordeiros perigosos (SPOSITO, 2001; SALLES, 2010) o que facilita a imposição de políticas de segregação e confinamento dessa população (WACQUANT, 2007). As crianças e os jovens pobres, que vivem em bairros violentos, com a presença de narcotráfico causam, conforme o imaginário social que se difunde, problemas na sociedade. Assim, viver em um determinado espaço social tem implicações sociais e pessoais que se manifestam no tipo de lazer escolhido, no estilo de vida adotado, no significado atribuído à escola e aos estudos e contribui para o estabelecimento de barreiras entre esses jovens e aqueles que vivem ou constituíram-se em diferentes contextos sociais, o que é particularmente verdade com os jovens considerados protagonistas de violência.

Os grupos sociais mais empobrecidos da população em função da degradação das relações de trabalho e das proteções sociais estão particularmente sujeitos aos processos de exclusão. Diferentes autores têm indicado que o rompimento com o Estado de Bem-Estar Social, a violência que se dissemina pela sociedade, a ruptura de laços sociais e o deslocamento das populações vulneráveis para a periferia são processos relacionados à exclusão social (CASTEL, 1997, 2004, 2008; PEGORARO, 2002; WACQUANT, 2001, 2007; YOUNG, 2002). Processo esse que é acentuado nos jovens e contribui para fortalecer a associação entre jovem pobre, morador da periferia com violência e periculosidade. Legitimando com isso, como diz Wacquant (2007), a "guetificação" dessa população, sendo o isolamento nesse caso erigido sobre quatro elementos: estigma, coação, confinamento territorial e segregação institucional.

Kowaric (1977), ao observar processos de marginalização na América Latina, em especial nas zonas urbanas, propõe conceituar grupos marginais como 
aqueles que se integram de formas peculiares às exigências de acumulação do capital. Embora em sua análise o autor chame atenção ao redimensionamento de formas de relação capital-trabalho. revisitando aspectos da teoria de dependência econômica, ele indica a necessidade de uma ampliação da noção ou conceito de marginalidade que abranja como base analítica o indivíduo, com o cuidado, porém, de que o indivíd

uo não seja tratado metodologicamente como unidade fechada à análise, evitando, com isso, incorrer em lógica de proposições, tais como: "os marginais são indivíduos que têm tais características e são marginais porque têm tais características" (KOWARIC, 1977, p.43). Kowaric (1977, p. 105) considera também que:

Boa parte da classe trabalhadora, e dentre estas os segmentos marginais, consome um "custo urbano" bastante diminuto, que se configura, por exemplo, no tipo de habitação e na forma como esta é construída, bem como no baixo grau de utilização dos serviços públicos, entre os quais: saúde, saneamento, energia elétrica e educação.

Pautados, então, no que Kowaric (1977) considera baixo custo urbano ${ }^{6}$ e formas peculiares de composição dessas populações às exigências do capitalismo atual, podemos ponderar que o fenômeno de exclusão social, envolve não só desigualdades econômicas, mas também formas de dominação sustentadas por relações de poder e por exclusões simbólicas (SALLES, 2010). Como diz Sawaia (2011), embora o conceito de exclusão social tenha a classe socioeconômica como referência principal, ele é um conceito abrangente na medida em que a desigualdade pode ser resultante de deficiência ou inadaptação individual, de injustiça e exploração social e de discriminação.

Em geral, exclusão social se refere a um estado de carência, de privação material, de segregação, de discriminação e de precariedade. É um conceito que se emprega quando se fala de desemprego, de jovens de periferia, próximos da delinquência e das drogas, de sem-teto e de outros grupos sociais considerados problemáticos (CASTEL, 2004, ZALUAR, 2004). Entretanto, os grupos de jovens não são homogêneos. Até mesmo as práticas culturais juvenis, como diz Dayrell (2007), não são homogêneas, pois em uma mesma periferia grupos de jovens podem se orientar para ações coletivas e/ou

\footnotetext{
6 Para a proposição da ideia sobre o baixo custo urbano ou, custo urbano diminuto Kowarick (1977) faz referência a trabalho de Quijano Obregon (1968) e refere-se a uma série de mecanismos característicos de ocupações da mão de obra marginal que contribuem para a manutenção e reprodução de níveis mínimos de subsistência de trabalhadores marginais ou não, mantendo em determinados espaços altas taxas de exploração de trabalho com potencial deterioração a eventual remuneração oferecida.
}

solidárias ou, ao contrário, para o uso de drogas e pequenas delinquências.

Tudo isso reforça a importância de se aprofundar a análise das questões que permeiam este estudo: quais são os espaços e locais pelos quais os jovens transitam, como os grupos de pertencimento são constituídos, como a escola e os estudos se inserem enquanto uma esfera da vida pela qual transitam e como os processos de inclusão/ exclusão social permeiam essas relações, principalmente entre aqueles considerados protagonistas de violência.

\section{O LAZER, O BAIRRO E A ESCOLA NO DEPOIMENTO DOS JOVENS CONSIDERADOS PROTAGONISTAS DE VIOLÊNCIA}

\section{O local onde vivem: os bairros e a comunidade}

A paisagem tipicamente urbana de bairros periféricos, os imaginários que a compõe figurados em quadros de ausência e precariedade, soam já incorporados às falas dos alunos entrevistados e que se tornam mais nítidas quando os jovens são indagados sobre aspectos específicos do bairro e sobre a atuação da prefeitura no local:
No bairro o que tem para fazer?
Nada (GV2).
Jogar bola de noite. Aqui não tem nada (GV2)
Eles (a prefeitura) falam que vão asfaltar, e até hoje está tudo nas pedras $(\mathrm{GV} 2)^{7}$.

Essa ausência de instâncias governamentais se soma à baixa ou quase nula presença de moradores vinculados a elas ou a instituições sociais, como a escola, vivendo no bairro, visto que apenas uma funcionária e duas professoras moram nesse local. Segundo eles, nenhum policial mora nesses bairros. A conotação negativa que reforça a ideia de ausência das instâncias governamentais, manifesta-se também nas falas quando mencionam a presença constante no bairro de usuários de drogas ilícitas e traficantes:

Conta como é o bairro.

É cheio de "nóia", você sai pra rua e o dia inteiro tem um fedô (GV1).

Como assim fedô?

É de maconha. (GV1)

\footnotetext{
7 Informação verbal obtida via grupo focal realizado no período de março de 2014 a fevereiro de 2015, coordenado pela pesquisadora Leila Maria Ferreira Salles, no Projeto de pesquisa: Jovens e Modos de Inserção Social: um estudo em bairros da periferia de Rio Claro. Financiamento CNPq.

8 O termo nóia engloba aparentemente todo e qualquer tipo de usuário de drogas, empregado pelo tráfico ou não, que consome o seu dia na busca / manutenção do seu vício.
} 
Tem dia que você tá vindo pra escola e tá lá o cheiro (GV1).

É em todos os lugares, pra eles não tem lugar (GV1). Aqui em Rio Claro não tem porra nenhuma. Aqui, serviço para menor

é vender droga $(\mathrm{GV} 2)^{9}$.

Mesmo com a generalização pontual de um dos entrevistados, há, nas manifestações, certo sentimento de abandono, de ausência de algum apoio e/ou tutela, de cuidado/zelo do Estado para com o bairro e com os entrevistados. Essa ausência ou a inoperância de equipamentos de Estado ou instâncias governamentais no bairro parecem promover vazios que permitem aos traficantes o estabelecimento de regras e arranjos próprios para a organização e funcionamento do local:

É assim: o ladrão robô a sua casa e você descobre quem é ele, se você for pra batê nele, eles pega e judia. Então os bandido ajuda você (GV2).

Que nem se uma pessoa se intrometeu com a mulher do outro, o cara vai lá e fala: fulano tal fez isso. Aí eles decidem se mata ele, se faz o que você quer, ou se não faz nada, porque é do bairro, porque eles comandam (GV2).

Eles falam as regras e as pessoas obedecem?

Não, eles não mandam as regras, eles agem normal, se alguém quisé, tipo mexe (com alguém do bairro) aí eles resolvem $(\mathrm{GV} 2)^{10}$.

Mesmo com as ausências e precariedades, com a presença de usuários de drogas ilícitas e traficantes, os entrevistados quando indagados sobre os seus sentimentos a respeito do bairro expressam gostar do local. Há um sentimento de afinidade dos entrevistados com o local, com o bairro, relacionado aos grupos de pertencimento, como os constituídos pelas relações de amizade. Nesse aspecto, se considerado, como diz Sennett (2008), que as formas dos espaços urbanos refletem a experiência corporal das pessoas, a carne não se faz pedra. $\mathrm{O}$ bairro mantém-se como marca de significação forte nas experiências dos entrevistados. Porém, a carência, a precariedade e a ausência do Estado mesmo sendo percebidas se mantêm distante de estimular alguma forma de "compaixão cívica" (SENNETT 2008, p.373), parecendo apenas facultar complexos filiativos resignados:

\footnotetext{
9 Informação verbal obtida via grupo focal realizado no período de março de 2014 a fevereiro de 2015, coordenado pela pesquisadora Leila Maria Ferreira Salles, no Projeto de pesquisa: Jovens e Modos de Inserção Social: um estudo em bairros da periferia de Rio Claro. Financiamento CNPq.

${ }^{10}$ Informação verbal obtida via grupo focal realizado no período de março de 2014 a fevereiro de 2015, coordenado pela pesquisadora Leila Maria Ferreira Salles, no projeto de pesquisa: Jovens e Modos de Inserção Social: um estudo em bairros da periferia de Rio Claro. Financiamento CNPq.
}

Fala que essa escola só tem maconheiro. Antigamente você passava no corredor pra ir pro recreio, você via gente fumando maconha. Agora não. Na época que a minha mãe estudava aqui não tinha nada disso. A diretora falou que se alguém fizesse bagunça apanhava $(\mathrm{GV} 1)^{11}$.

A resignação que tange a passividade, é, talvez, a única forma de ação que é vislumbrada, de modo que quando indagados sobre o que pode ser feito para melhoria do bairro, os participantes do grupo GV1 dizem: "tirá esses nóia do bairro; mas todo lugar é assim; tinha que fazê um bairro só pra nóia" ${ }^{12}$ ".

As análises indicam que a existência e a vivência de elementos comuns na comunidade que poderiam facilitar uma agregação e tornar a comunidade espaço de filiação é simultâneo a desejos de exclusão e/ou de restrição ao convívio com os outros jovens moradores no local. Mesmo sendo os jovens entrevistados, lembramos aqui, considerados protagonistas de violência no âmbito escolar, usuários de drogas e autores de pequenas delinquências.

A relação com outras pessoas do bairro parece deste modo, não transcender para além de uma estada simultânea. Ruas, praças e outros espaços públicos acabam passíveis de serem significados apenas como espaços de simples trânsito. O bairro, com seus moradores e outros grupos de jovens, parece configurar para os entrevistados um espaço fragmentado, pulverizado em instâncias estanques, embora suas vidas cotidianas transcorram nesse local. $\mathrm{O}$ bairro em que vivem surge nas falas como um lugar de trânsito que não favorece complexos filiativos, nem mesmo entre pares, visto que críticas aos nóias estão, embora de modo ambivalente, sempre presentes nas falas.

\section{O uso do tempo livre, as atividades de lazer e os locais frequentados}

Solicitados a comentar sobre as formas de aproveitamento do tempo livre, muitas vezes confundidos exclusivamente com contraturnos escolares, há a sugestão nos depoimentos de ocupação desse tempo com atividades como: ficar em casa, andar de bicicleta, empinar pipas, ir a shoppings e, eventualmente, a baladas e igrejas. Os afazeres domésticos são mais organizados em razão do gênero e da eventual incidência de trabalhos formais e

\footnotetext{
${ }^{11}$ Informação verbal obtida via grupo focal realizado no período de março de 2014 a fevereiro de 2015 coordenado pela pesquisadora Leila Maria Ferreira Salles, no projeto de pesquisa: Jovens e Modos de Inserção Social: um estudo em bairros da periferia de Rio Claro. Financiamento $\mathrm{CNPq}$

${ }^{12}$ Informação verbal obtida via grupo focal realizado no período de março de 2014 a fevereiro de 2015, coordenado pela pesquisadora Leila Maria Ferreira Salles, no projeto de pesquisa: Jovens e Modos de Inserção Social: um estudo em bairros da periferia de Rio Claro. Financiamento CNPq.
} 
informais. Já o acesso a atividades noturnas como as idas a baladas são negociados com familiares:

Meus pais falam que posso ir e se eu não beber cerveja posso ficar até às 4 horas. Aí eu vou e não bebo cerveja, bebo caipirinha, caipirinha com vinho, essas coisas. Deixa sair, só fala "toma cuidado menina" (GV1). Que controlar a hora, dependendo da hora. Mas tem vez que eu saio e volto só no outro dia $(\mathrm{GV} 2)^{13}$.

É na relação com as famílias que marcos regulatórios às atividades são estabelecidos, seja para a sua adoção ou para estruturação de formas de transgressão.

A proibição dos pais ao uso de drogas ilícitas está presente na fala de todos os entrevistados. Incorre, porém, nas falas, a constante presença e facilidade de acesso a drogas lícitas e ilícitas. $\mathrm{O}$ acesso a drogas ilícitas parece única e exclusivamente restrito ao desejo dos entrevistados, não possuindo nenhum outro fator complicador para a posse ou uso:

Eu não uso. A pessoa usa se ela quiser. Não tem lei que prenda usuário. Os outros usam se quiser. Porque se eu chegar com um baseado e oferecer, os outros fuma se quiser. Agora se os caras chegarem para mim e me oferecerem outro tipo de droga e eu não quiser, eu não quero e pronto $(\mathrm{GV} 2)^{14}$.

As eventuais intervenções de familiares parecem pouco efetivas como marcas a proibições ao uso de drogas, parecendo mais efetivas em relação à interdição aos espaços que se quer frequentar.

Embora menos recorrentes, devido às condições de mobilidade que dificulta a frequência a espaços extrabairros, os jovens vão a um bar localizado em um posto de gasolina, que concentra pessoas de faixa etária similar ao dos grupos compostos na pesquisa aos finais de semana, ao shopping center, ao Grêmio Recreativo (clube social e poliesportivo), e a dois equipamentos públicos de lazer mantidos pela Prefeitura Municipal. Esses dois últimos consistem em complexos de lazer e esportivo mantidos pela Prefeitura Municipal onde se pode jogar bola, empinar pipa, andar de bicicleta, andar de skate e praticar esporte. Porém, embora haja menção nas falas a idas ao shopping center da cidade e ao Grêmio Recreativo, os jovens entrevistados em geral não adentram estes espaços, permanecendo aglomerados em seu entorno, o

\footnotetext{
${ }^{13}$ Informação verbal obtida via grupo focal realizado no período de março de 2014 a fevereiro de 2015 coordenado pela pesquisadora Leila Maria Ferreira Salles, no Projeto de pesquisa: Jovens e Modos de Inserção Social: um estudo em bairros da periferia de Rio Claro. Financiamento $\mathrm{CNPq}$

${ }^{14}$ Informação verbal obtida via grupo focal realizado no período de março de 2014 a fevereiro de 2015 coordenado pela pesquisadora Leila Maria Ferreira Salles, no Projeto de pesquisa: Jovens e Modos de Inserção Social: um estudo em bairros da periferia de Rio Claro. Financiamento CNPq.
}

que contribui para a presença ostensiva de seguranças e policiais nesses locais. Também no bar mencionado, a presença de policiais é frequente visto que fica em frente a um centro comercial e de lazer constituído por lojas, restaurantes e bares frequentados pela elite local.

$\mathrm{O}$ denominador comum a esses locais parece se resumir na presença constante dos nóias e no policiamento ostensivo. Os nóias e as maneiras de estada deles no bairro, na escola e nos espaços de lazer são recorrentes nas falas:

Roubam as coisas, até o gira-gira do parquinho os "nóia" roubaram. Também roubam o fio pra vender o cobre e comprar "pedra", outro dia roubaram até o fio da escola e ficamos sem energia por uma semana (GV1). Às vezes, quebra a luz do poste $(\mathrm{GV} 1)^{15}$.

O termo nóia surge quase como categoria englobando aparentemente todo e qualquer tipo de usuário, empregado pelo tráfico ou não, que consome o dia na manutenção do seu vício. Referências a demais grupos são esparsas e quando o há são descrições de comportamentos, posturas ou condutas individuais, em geral, relacionadas a condutas agressivas: brigas, que são, segundo eles, motivadas pelo fato de que não se deve permitir que um jovem mexa com a namorada ou namorado do outro. Excluídos os nóias, a única menção mais aguda a algo que delineie alguma existência de um grupo que possa constitui-se com características identitárias próprias, estão nos jovens que frequentam igrejas.

Porém os nóias retornam sempre às falas fazendo parte do cotidiano de vida dos entrevistados, seja como estorvo, seja como mero elemento da paisagem urbana e com aspectos até de naturalização, estabelecendo-se como normas para certas condutas:

É muito difícil você encontrá um nóia que fala que terminô os estudos (GV1).

Eles param (GV1).

Eles foram pro mau caminho, eu falei pra ele que se ele quisé ser meu amigo ainda sai desse caminho (GV1). Esse aí só fica assistindo televisão (GV2).

Ele só fica tomando chá. (fumando maconha) (GV2). Oh, os caras aqui, chamando eu de nóia. Chá é droga? Chá é chá $(\mathrm{GV} 2)^{16}$.

As falas, então, parecem estar eivadas de contradição: ao mesmo tempo em que há certa crítica aos nóias, eles

\footnotetext{
${ }^{15}$ Informação verbal obtida via grupo focal realizado no período de. março de 2014 a fevereiro de 2015, coordenado pela pesquisadora Leila Maria Ferreira Salles, no projeto de pesquisa: Jovens e Modos de Inserção Social: um estudo em bairros da periferia de Rio Claro. Financiamento $\mathrm{CNPq}$

${ }^{16}$ Informação verbal obtida via grupo focal realizado no período de março de 2014 a fevereiro de 2015 coordenado pela pesquisadora Leila Maria Ferreira Salles, no projeto de pesquisa: Jovens e Modos de Inserção Social: um estudo em bairros da periferia de Rio Claro. Financiamento $\mathrm{CNPq}$
} 
próprios são considerados, pelos gestores escolares e por eles próprios, ao se acusarem mutuamente de serem usuários de drogas, nóias. Talvez, como uma tentativa de resolver esse conflito, é que se grafa a existência de um imaginário de que algumas formas de uso de drogas ilícitas são toleráveis e até comuns desde que a rotina de uso não rompa a fronteira ou afete os demais afazeres cotidianos: "Eu fumo droga dentro da minha casa, para ninguém ver. Você tem que fumar é para você e não fumar para os outros ${ }^{17 "}$ '(GV2).

O cotidiano povoado pelos nóias atrai consigo o aparato policial para os espaços destinados à estada e o convívio dos entrevistados. As ações policiais figuram nas falas, ora com truculência, ora com naturalidade, ora associado aos nóias, ora associado a eles próprios:

Eles (os nóias) não têm medo da polícia. A polícia que tem medo deles, se passa um carro de polícia e tem uma rodinha, eles sabe que é nóia, eles não para. Eles passa reto e finge que nem viu (GV1).

Já fui parado pela polícia. Eu tava vindo da igreja, eles tava fazendo ronda por ali, revistou, viu que não tinha nada, aí libero (GV2).

Eu matei aula e fui pro Lago Azul, ai eles paro eu e o meu colega, eles revisto e mando a gente ir embora, aí fomos embora $(\mathrm{GV} 1)^{18}$.

Como essas falas começam a indicar o policiamento ostensivo é elemento comum nos locais que frequentam:

Eu ia bastante no shopping. Mas ficava muita gente lá fora e os homens (polícia) chegavam dando tiro de borracha (GV2).

No shopping (a segurança) não deixa. Porque a gente fica bebendo na frente (GV2).

Nós vindo uma vez do Grêmio o cara com cavalo quase passou em cima de nós (GV2).

Ah, eu já fui bastante no Grêmio, mas só vi (drogas) uma vez. Lá na 29, aàs vezes tem (drogas). Esses dias mesmo, um policial caiu do cavalo lá no Grêmio, aí teve tiro de borracha. Aí ele caiu do cavalo e o cavalo começou a pisar em cima dele. Eu fiquei assustado com os tiros de borracha (GV1).

E por que dos tiros de borracha?

Frescura, porque fica muita gente lá fora $(\mathrm{GV} 1)^{19}$.

${ }^{17}$ Informação verbal obtida via grupo focal realizado no período de março de 2014 a fevereiro de 2015 coordenado pela pesquisadora Leila Maria Ferreira Salles, no projeto de pesquisa: Jovens e Modos de Inserção Social: um estudo em bairros da periferia de Rio Claro. Financiamento CNPq.

${ }^{18}$ Informação verbal obtida via grupo focal realizado no período de março de 2014 a fevereiro de 2015 coordenado pela pesquisadora Leila Maria Ferreira Salles, no projeto de pesquisa: Jovens e Modos de Inserção Social: um estudo em bairros da periferia de Rio Claro. Financiamento CNPq.

${ }^{19}$ Informação verbal obtida via grupo focal realizado no período de março de 2014 a fevereiro de 2015 coordenado pela pesquisadora Leila Maria Ferreira Salles, no projeto de pesquisa: Jovens e Modos de Inserção Social: um estudo em bairros da periferia de Rio Claro. Financiamento CNPq.
Os espaços de lazer figuram assim conectados à lógica das ruas. Mas é nesse quadro que os entrevistados tramam seus enredos e tecem suas relações com os outros. A rua, os jovens do bairro e de outros bairros e a escola surgem como espaços significativos na composição das amizades e parcerias para os afazeres vinculados ao tempo livre por facilitarem a frequência simultânea de pessoas da mesma faixa etária. A escola parece ser aos entrevistados referência para compor parcela dos considerados amigos: "amigos tem da rua, da escola, da Escola 2, de outros lugares que não estudam aqui” (GV1).

As saídas com os amigos estão presentes nos depoimentos, mas o conjunto das falas sugere um número baixo de relações de amizade e, embora isto não seja de fato quantificável, encontramos manifestações sobre substituição de atividades com amigos em favor de atividades com familiares, como pais, tios e primos.

As relações com os amigos não parecem ser duradouras, estando sujeitas a desavenças, conflitos e brigas que levam, muitas vezes, ao rompimento dessas relações. Há, assim a sugestão sobre a manutenção de complexos filiativos tênues amparados mais em circunstâncias de estadas confluentes em espaços comuns e a frequência a mesma escola, em detrimento da presença de qualquer outro elemento gregário ou traço filiativo comunitário. Os complexos filiativos nos espaços de lazer, onde as relações de amizades preponderam parecem ser fluidos, pouco duradouros e permanentes, de modo que os espaços para o convívio compartilhados parecem não ser suficientes para o estabelecimento de marcos para as relações cotidianas e para a homogeneização de ações e formas de enfrentamento das demandas diárias. Os enfrentamentos cotidianos são tratados de maneiras diversificadas compondo, aparentemente, um conjunto multifacetado de pequenos dramas individuais.

Da mesma forma como observamos em relação ao bairro, a existência de alguns elementos comuns não parece ser base forte o suficiente que favoreça a tessitura de complexos filiativos. Resta refletir se a escola como espaço de convergência e estadas compartilhadas se faz catalizadora para outras formas de filiação.

\section{A escola}

Distinguindo-a dos demais espaços, os entrevistados retratam a escola como espaço autônomo e desconectado das lógicas que imperam no bairro e nos lugares de lazer. Porém, a escola enquanto espaço de confluência para estadas simultâneas e referência para a composição de possíveis amizades, apresenta alguns traços similares aos dos ambientes de lazer. Assim, essa diferenciação entre a escola e demais espaços frequentados é tensionada na medida em que a escola é percebida como penetrada 
pelo bairro e suas lógicas, como dizem os integrantes do Grupo GV1:

A escola é uma bosta.

Minha mãe preferia que eu estudasse no $(. . .)^{20}$. Porque ela falou que só da confusão nessa escola.

A escola é mal falada.

Outros falam que é igual cadeia. Aqui a única coisa diferente é que podemos sair.

Fala que a escola é ruim, é só bagunça, só tem traficante.

E tem traficante?

Não. Só no bairro ${ }^{21}$.

Pensar a escola como espaço autônomo, embora inserida no bairro, é também difícil quando os entrevistados falam das depredações e atos de vandalismo praticados por jovens na escola, a exemplo deste diálogo entre alunos da Escola 1:

Já quebraram o banheiro das meninas.

É gente de dentro da escola.

Que nem o mês passado, roubaram.

Eu acho que deveria chamar a ronda escolar. Mas não vem mais. Eu acho que deveria ter ronda escolar sempre em volta da escola, porque sempre tem gente pulando o muro, tem gente que tá na rua $\mathrm{e}$ taca bomba aqui dentro ${ }^{22}$.

Os alunos, porém, em uma tentativa de desconectar a lógica da rua da que vigora na escola e demarcar com isso uma descontinuidade no contínuo escola/bairro, tendem a explicar esses comportamentos associando-os à lógica própria da escola: "Eu acho que eles guardam mágoa dos professores, acho que eles têm raiva" $(\mathrm{GV} 1)^{23}$.

Nas falas dos entrevistados da Escola 1, além das condições físicas do prédio escolar consideradas ruins e a incidência quase regular de atos depredatórios às instalações, a escola padece também com a recorrente falta de professores, contribuindo essas ausências para a elaboração e manutenção de imaginários depreciativos

\footnotetext{
${ }^{20}$ Cita o nome de escola diferente da Escola 1 e Escola 2.

${ }^{21}$ Informação verbal obtida via grupo focal realizado no período de março de 2014 a fevereiro de 2015 coordenado pela pesquisadora Leila Maria Ferreira Salles, no projeto de pesquisa: Jovens e Modos de Inserção Social: um estudo em bairros da periferia de Rio Claro. Financiamento CNPq.

${ }^{22}$ Informação verbal obtida via grupo focal realizado no período de março de 2014 a fevereiro de 2015, coordenado pela pesquisadora Leila Maria Ferreira Salles, no projeto de pesquisa: Jovens e Modos de Inserção Social: um estudo em bairros da periferia de Rio Claro. Financiamento CNPq.

${ }^{23}$ Informação verbal obtida via grupo focal realizado no período de março de 2014 a fevereiro de 2015, coordenado pela pesquisadora Leila Maria Ferreira Salles, no projeto de pesquisa: Jovens e Modos de Inserção Social: um estudo em bairros da periferia de Rio Claro. Financiamento CNPq.
}

sobre o local: "Porque falta professor todo dia. Tem vez que nóis vai pra escola e volta embora. Aí, eu reclamo de tudo, porque eu acordo de manhã e não gosto. Aqui tenho uma ou duas aulas e vou embora" (GV1) ${ }^{24}$.

Os entrevistados da Escola 2 mantêm um imaginário sobre a escola ser ruim, reclamando da postura dos profissionais:

Uma coisa que eu acho errado é, só porque a gente chega dois ou três segundinhos atrasado, eles colocam a gente para fora. $\mathrm{O}$ professor segurou a gente por 10 minutos, ai a gente foi lá e saiu. Ele foi lá e segurou na menina ela abaixou e saiu. Ele foi lá na diretoria chorar e falar que a menina deu um soco na barriga dele. É mentira, ela só abaixou assim e saiu correndo (GV2) ${ }^{25}$.

Há, no conjunto das narrativas, indicativos que a escola é um local potencialmente hostil e favorável à opressão. As reclamações sobre a escola e os educadores, ou seja, as queixas sobre as incivilidades que ocorrem no âmbito escolar são frequentes nas falas:

Ah porque já teve briga com professor, às vezes dá confusão com eles aqui (GV1).

Já teve um professor que bateu no menino (GV2).

Outro dia a professora veio me acusar de estar tirando sarro da cara dela (GV2).

Tempo atrás um professor me bateu né, daí ele catou e foi embora. Todos os professores têm implicância comigo, daí qualquer coisinha sobra pra mim. $(\mathrm{GV} 1)^{26}$

$\mathrm{Na}$ Escola 2, a separação escola bairro parece ser, contudo, mais demarcada, talvez pelas melhores condições de preservação física da escola. Assim, quando indagados sobre a escola ser depredada, os alunos do GV2 dizem: "Nunca, pelo que eu saiba não. Só de jogar pedra. Mas de gente de fora, de jogar de lá de fora aqui dentro".

Não é referida nas falas dos dois grupos alguma abertura das escolas aos finais de semana aos alunos. Os relatos não fazem referência à existência de qualquer projeto interno ou atividades para a integração dos alunos,

\footnotetext{
${ }^{24}$ Informação verbal obtida via grupo focal realizado no período de março de 2014 a fevereiro de 2015, coordenado pela pesquisadora Leila Maria Ferreira Salles, no projeto de pesquisa: Jovens e Modos de Inserção Social: um estudo em bairros da periferia de Rio Claro. Financiamento CNPq.

${ }^{25}$ Informação verbal obtida via grupo focal realizado no período de março de 2014 a fevereiro de 2015, coordenado pela pesquisadora Leila Maria Ferreira Salles, no projeto de pesquisa: Jovens e Modos de Inserção Social: um estudo em bairros da periferia de Rio Claro. Financiamento $\mathrm{CNPq}$

${ }^{26}$ Informação verbal obtida via grupo focal realizado no período de março de 2014 a fevereiro de 2015, coordenado pela pesquisadora Leila Maria Ferreira Salles, no projeto de pesquisa: Jovens e Modos de Inserção Social: um estudo em bairros da periferia de Rio Claro. Financiamento CNPq.
} 
ex-alunos e população circunvizinha ao espaço escolar, seja nos contraturnos escolares seja aos finais de semanas. A presença da família junto à escola parece restringir-se aos chamamentos da direção para alguma manifestação sobre a conduta dos filhos.

Ninguém pode vir. Eles não deixa. Por exemplo, tem festa um dia, daí os do horário da manhã, só a turma da manhã que pode fica de manhã. Eles faz de tarde só pra turma da tarde. Antes podia entrar alguém da família para ver a gente dançar, agora não pode $(\mathrm{GV} 2)^{27}$.

O espaço escolar vai, então, constituindo-se, nas falas dos entrevistados, como espaço interditado ou de interdições, local pouco aprazível e de estadas tempestivas. Diferenciado da rua ou dos espaços para o lazer pela especificidade que é própria da instituição escolar, esse espaço se confunde, às vezes, com a rua ao comutar elementos com esse local:

Eu já usei droga dentro da escola, já fumei, usei êxtase.

É só você ficar de boa. Ficar quieto.

E por que vocês usam na escola?

Ah, porque a gente está de saco cheio dos professores que só querem saber de mandar a gente para fora. $(\mathrm{GV} 2)^{28}$

De modo semelhante, os integrantes do Grupo GV1 dizem: "Quantos dias nóis tava em aula e tinha neguinho fumando maconha".

Essa confusão/mistura não se faz, parece-nos, como processo intencional e visível aos próprios alunos parecendo ser deflagrado pela perda gradual da identidade do espaço escolar incrustada na especificidade dos seus fazeres. Porém, desse modo, se o espaço escola pode se confundir com a rua, faz-se local para lazer; esquizofreniza-se pelo gradual apagamento de sua especificidade. Nesse jogo, embora quando indagados sobre o que pretendem para o futuro, algumas respostas remetam à necessidade do ensino superior, o estudo ou a obtenção de um diploma escolar acaba não se caracterizando como base para a elaboração de projetos de vida futura.

Parece-nos, além do que, que os espaços escolares circunscritos pelos seus muros, porém em processos de ressignificação dos seus sentidos, mesmo caracterizados

\footnotetext{
${ }^{27}$ Informação verbal obtida via grupo focal realizado no período de março de 2014 a fevereiro de 2015, coordenado pela pesquisadora Leila Maria Ferreira Salles, no projeto de pesquisa: Jovens e Modos de Inserção Social: um estudo em bairros da periferia de Rio Claro. Financiamento CNPq.

${ }^{28}$ Informação verbal obtida via grupo focal realizado no período de março de 2014 a fevereiro de 2015, coordenado pela pesquisadora Leila Maria Ferreira Salles, no projeto de pesquisa: Jovens e Modos de Inserção Social: um estudo em bairros da periferia de Rio Claro. Financiamento CNPq.
}

como espaços de confluência e estadas alongadas, não se figuram, a exemplo dos locais de lazer e o bairro, como espaços privilegiados à estruturação de complexos filiativos que transcendam as estadas. Ao ganhar contornos de rua, os espaços escolares atraem para si alguns de seus imaginários, remetendo os entrevistados além da estada em local potencialmente hostil, à necessidade de composição de toda uma forma de atuação que parece configurar, simbolicamente o outro - a escola e seus atores - como eventual agressor.

\section{Algumas CONSIDERAÇõeS FINAIS}

De modo geral, a vida para os jovens entrevistados está circunscrita ao próprio bairro, à ida a um ou outro espaço de lazer, à rua e à escola. Espaços esses que se constituem em território e palco para o convívio cotidiano. Nessa circunscrição, as características e as condições sobre a moradia em bairro de periferia urbana pobre e o pertencimento a populações de baixa renda surgem nas falas demarcando aonde ir, o que fazer, o acessível e as interdições. Nesse sentido, este estudo converge com as constatações e afirmações feitas, entre outros, por Abramovay (2002, 2009); Dayrell, (2005), Herschmann (2000) Maiolino e Mancebo (2005). As condições socioeconômicas como a de ser jovem morador da periferia urbana pertencente ao extrato socioeconômico mais empobrecido da população delimitam espaços e modos de inserção social. Conflui ainda com a ideia de Kowaric de baixo custo urbano para a sustentação e manutenção dessas populações entre as quais predomina o trabalho não formal, o trabalhador autônomo, e com isso criando "condições para que a classe trabalhadora, marginal ou não, se reproduza a níveis mínimos de subsistência" (KOWARIC, 1977, p. 105).

As características do bairro e de morar em uma área urbana empobrecida da cidade aparecem de modo recorrente nas falas, indicando o quanto as vidas cotidianas são marcadas por essas características. Particularidade essa que adentra nas escolas que, assim como os jovens, evidenciam marcas próprias do fato de estarem presentes em bairros da periferia urbana empobrecida e, portanto, sujeitas a vandalismos, depredações, convívio com usuários de drogas ilícitas. Características que se somam e facilitam a confusão entre escola e rua, ou seja, que a lógica da rua invada a escola que fica assim sujeita aos mesmos balizadores.

Porém, os jovens parecem desconsiderar as determinações externas que se impõem e configuram as características dos bairros onde vivem, dos espaços de lazer e das escolas que frequentam, tendendo a entender que a vida que cada um vive e os diferentes espaços pelos quais circulam são espaços circunscritos que 
respondem apenas a sua lógica interna. Fato esse que dificulta perceber que os modos pelo quais se inserem na sociedade, mesmo no plano microssocial, como discutido neste texto, são determinados por processos de inclusão/ exclusão social aos quais estão sujeitos e dificultando, em última instância, formas de resistência a eles.

Para os jovens, a vida em comum parece se resumir a estar junto em um aglomerado de pessoas, o que dificulta a formação de um senso de coletivo e de coletividade apesar da existência e da vivência de elementos comuns que poderiam facilitar uma associação e tornar a comunidade um espaço de filiação. Ao perceberem os locais em que vivem e frequentam como circunscritos e isolados, o bairro, os locais para o lazer, a rua e até mesmo a escola surgem nas falas como locais de estadas granulares e desconexas, sendo passíveis de serem significados apenas como espaços de simples trânsito mantendo-se como continente de pessoas isoladas, espaços de aglomeração para estadas concomitantes, mas que não favorecem a composição de qualquer vínculo filiativo diferente do estar ali. A existência de alguns elementos comuns, como exemplo a partilha de espaços ou condições sociais similares, não parece ser base forte o suficiente para a tessitura de complexos de afiliação.

Embora morem no mesmo bairro e frequentem os mesmos espaços os jovens parecem não se perceber como tendo vidas compartilhadas e esse não compartilhamento dos dramas vividos contribui, assim nos parece, para a perda de algum sentido de conjunto nas relações cotidianas. Tal fato, ou seja, a composição do cotidiano em espaços selados cuja paisagem urbana deles se desvincula (SENNETT, 2008) dificulta a percepção da ação política ou de algum exercício de resistência e intervenção no espaço e prejudica leituras e interpretações sobre o cotidiano ser composto por fatores que transcendem as fronteiras físicas e simbólicas do imediatamente vivido.

Ao considerarmos que a possibilidade de comunidade, mesmo que frágil, reside também em alguma existência de "entendimento compartilhado do tipo 'natural' e 'tácito'", (BAUMAN, 2003, p. 16), nas narrativas dos participantes aparentemente não há compartilhamento de algum entendimento, incorrendo as reflexões em exames pontuais e individuados. Mesmo o espaço escolar ao esquizofrenizar-se em rua desfigurase como potencial ponto para fuga. A gradativa perda da sua especificidade como espaço privilegiado à reflexão (ARENDT, 2011), catalisa o esvaecimento de resistências. Desse modo, o espaço escolar passa a flutuar do ainda eventual ponto para construção de fuga das relações cotidianas e transformação do próprio modo de vida, para local de fuga dos afazeres domésticos ou repressão familiar.
A percepção de um destino comum remeteria, assim nos parece, a algum rascunho de ação potencialmente transformadora. Porém, sendo o coletivo reduzido a estadas simultâneas e a uma indiferenciação de espaços onde bairro, locais de lazer, escola e rua se confundem, as possibilidades de transformação do espaço e das relações locais parecem cada vez mais difíceis, obstaculizando até mesmo as possibilidades de fugas individuais que para sua efetivação demandem a adoção de alguma ação ou projetos partilhados.

Enfim, os depoimentos remetem à ideia de um aglomerado de pessoas que vivem juntas o seu dia a dia, aonde cada um vai vivendo sua vida como dá. Ou seja, não são vidas compartilhadas. Isto tudo evidencia que os modos de inserção social dos jovens devem ser analisados em suas particularidades, visando desvelar os processos de exclusão e as possibilidades de resistência implícitos neles, pois como diz Castel (2004), a inserção social não se resume a inserção profissional e é uma obrigação da coletividade que deve se mobilizar para propor contratos de inserção.

\section{REFERÊNCIAS}

ABRAMO, H. W. Cenas juvenis: punks e darks no espetáculo urbano. São Paulo: Scritta, Página Aberta, 1994. 172 p.

ABRAMOVAY, M.; ANDRADE, E. R.; ESTEVES, L. G. (org.). Juventudes. Outros olhares para a diversidade. Brasília: UNESCO, 2009. 248 p.

ABRAMOVAY, M., CASTRO, M. G. Jovens em situação de pobreza, vulnerabilidades sociais e violências. Cadernos de Pesquisa, São Paulo, n. 116, p. 143-176, jul. 2002. Disponível em: http://www.scielo.br/scielo.php. Acesso em: 9 fev. 2012.

ARENDT, H. Entre o passado e o futuro. 7. ed. São Paulo: Perspectiva, 2011. 348 p.

BARDIN, L. Análise de conteúdo. Lisboa, Edições 70, 1988. $225 \mathrm{p}$.

BAUMAN, Z. Comunidade: a busca por segurança no mundo atual. Rio de Janeiro: Zahar, 2003. 141 p.

CASTEL, R. A dinâmica dos processos de marginalização: da vulnerabilidade a desfiliação. CADERNO CRH, Salvador, n. 26/27, p. 19-40, jan./dez. 1997. Disponível em: http://www. cadernocrh.ufba.br. Acesso em: 5 nov. 2002.

CASTEL, R. A discriminação negativa: cidadãos ou autóctones? Petrópolis: Vozes, 2008. 136p.

CASTEL, R. Las trampas de la exclusión: trabajo y utilidad social. Buenos Aires: Topía, 2004. 87 p.

DAYRELL, J. A Música entra em cena: o rap e o funk na socialização da juventude. Minas Gerais: Editora UFMG, $2005.303 \mathrm{p}$. 
DAYRELL, J. A escola "faz" as juventudes? Reflexões em torno da socialização juvenil. Educação e Sociedade, Campinas, v. 28, n. 100, p. 1105-1128, 2007. Disponível em: http:/www.scielo.br/scielo.php. Acesso em: 5 out. 2011.

GATTI, B. A. Grupo focal na pesquisa em Ciências Sociais e Humanas. Brasília: Liber Livro Editora, 2005. 86 p.

HERSCHMANN, M. O funk e o hip hop invadem a cena. Rio de Janeiro: Editora da UERJ, 2000. 340 p.

KOWARIC, L. Capitalismo e Marginalidade na América Latina. Rio de Janeiro: Paz e Terra, 1977. 187 p.

LOPES, J. R. Exclusão social e controle social: estratégias contemporâneas de redução da sujeiticidade. Psicologia \& Sociedade, v. 18, n. 2, p. 13-24, maio/ago. 2006. Disponível em: http://www.scielo.br/pdf/psoc/v18n2/02.pdf. Acesso em: 4 set. 2008 .

MAIOLINO, A. L. G.; MANCEBO, D. Análise histórica da desigualdade: marginalidade, segregação e exclusão. Psicol. Soc., Porto Alegre, v. 17, n. 2, p. 14-20, ago. 2005. Disponível em: http://www.scielo.br/scielo.php. Acesso em: 4 set. 2008.

PAIS, J. M. A construção sociológica da juventude - alguns contributos. Análise Social, Lisboa, n. 1-2, p. 139-165, 1990.

PEGORARO, J. Notas Sobre los jóvenes portadores de violencia juvenil en el marco de las sociedades posindustriales. Sociologías, Porto Alegre, n. 8, p. 276-317, 2002.

RIBEIRO, M. Exclusão e educação social: conceitos em superfície e fundo. Educação e Sociedade, Campinas, v. 27, n. 94, p. 155-178, 2006. Disponível em: http://www.scielo.br/ scielo.php. Acesso em: 20 jan. 2010.

SALLES, L. M. F. Jovens, escola e violência: alguns apontamentos sobre o processo de inclusão e exclusão simbólica. In: SALLES, L. M. F; SILVA. J. M. A. de P. (org.). Jovens, violência e escola: um desafio contemporâneo. São Paulo: UNESP: Cultura Acadêmica, 2010. p. 45-70.

SALLES, L. M. F. Adolescência, escola e cotidiano: um discurso contrastante entre o genérico e o particular. Piracicaba, São Paulo: UNIMEP, 1998. 173 p.

SAWAIA, B. Exclusão ou inclusão perversa? In: SAWAIA, B. (org.). As artimanhas da Exclusão. Analise psicossocial e ética da desigualdade social. 11. ed. Petrópolis: Vozes, 2011. p. 7-16.

SENNETT, R. Carne e pedra: o corpo e a cidade na civilização ocidental. Rio de Janeiro: Bestbolso, 2008. $417 \mathrm{p}$.

SPÓSITO, M. P. Um breve balanço da pesquisa sobre violência escolar no Brasil. Educação e Pesquisa, São Paulo, v. 27, n. 1, p. 87-103, 2001. Disponível em: http://www.scielo. br/scielo.php. Acesso em: 13 abr. 2005.

WACQUANT, L. As Prisões da Miséria. Rio de Janeiro: Zahar, 2001. 174p.
WACQUANT, L. Punir os pobres: a nova gestão da miséria nos Estados Unidos. 3. ed. Rio de Janeiro: Revan, 2007. 474p.

YOUNG, J. A sociedade excludente: exclusão social, criminalidade e diferença na modernidade recente. Rio de Janeiro: Revan, 2002. 314p.

ZALUAR, A. Integração perversa: pobreza e tráfico de drogas. Rio de Janeiro: FGV, 2004. 438 p.

Recebido em: 19/4/2017.

Aprovado em: 27/12/2018.

Publicado em: 30/4/2019.

Endereço para correspondência:

Luciano Plez de Melo

Rua Costa Pereira, 91 - Centro

13730-360, Mococa, SP, Brasil

\section{Autores:}

LuCiano Plez de Melo

Doutor em Educação. Universidade Estadual Paulista (UNESP), Rio Claro, SP, Brasil.

Orcid: https://orcid.org/0000-0002-9335-7046

E-mail: luciano.plez@gmail.com

LeILA Maria Ferreira SALLES

Doutora em Educação. Universidade Estadual Paulista (UNESP), Rio Claro, SP, Brasil.

Orcid: https://orcid.org/0000-0002-8117-1551

E-mail: leila.salles@unesp.br 